\title{
BMJ Open Examining changes in the equity of physician distribution in Japan: a specialty-specific longitudinal study
}

Koji Hara, Susumu Kunisawa, Noriko Sasaki, Yuichi Imanaka

To cite: Hara K, Kunisawa S, Sasaki N, et al. Examining changes in the equity of physician distribution in Japan: a specialty-specific longitudinal study. BMJ Open 2018;8:e018538. doi:10.1136/ bmjopen-2017-018538

- Prepublication history and additional material for this paper are available online. To view these files, please visit the journal online (http://dx.doi. org/10.1136/bmjopen-2017018538).

Received 5 July 2017 Revised 6 November 2017 Accepted 21 November 2017

CrossMark

Department of Healthcare Economics and Quality Management, Graduate School of Medicine, Kyoto University, Kyoto, Japan

Correspondence to Dr Yuichi Imanaka; imanaka-y@umin.net

\section{ABSTRACT}

Objectives In this longitudinal study, we examined changes in the geographical distribution of physicians in Japan from 2000 to 2014 by clinical specialty with adjustments for healthcare demand based on population structure.

Methods The Japanese population was adjusted for healthcare demand using health expenditure per capita stratified by age and sex. The numbers of physicians per 100000 demand-adjusted population (DAP) in 2000 and 2014 were calculated for subprefectural regions known as secondary medical areas. Disparities in the geographical distribution of physicians for each specialty were assessed using Gini coefficients. A subgroup analysis was conducted by dividing the regions into four groups according to urban-rural classification and initial physician supply. Results Over the study period, the number of physicians per 100000 DAP decreased in all specialties assessed (internal medicine: $-6.9 \%$, surgery: $-26.0 \%$, orthopaedics: $-2.1 \%$, obstetrics/gynaecology (per female population): $-17.5 \%)$ except paediatrics (+33.3\%) and anaesthesiology $(+21.1 \%)$. No reductions in geographical disparity were observed in any of the specialties assessed. Geographical disparity increased substantially in internal medicine, surgery and obstetrics and gynaecology(OB/GYN). Rural areas with lower initial physician supply experienced the highest decreases in physicians per 100000 DAP for all specialties assessed except paediatrics and anaesthesiology. In contrast, urban areas with lower initial physician supply experienced the lowest decreases in physicians per 100000 DAP in internal medicine, surgery, orthopaedics and $\mathrm{OB} / \mathrm{GYN}$, but the highest increase in anaesthesiology.

Conclusion Between 2000 and 2014, the number of physicians per 100000 DAP in Japan decreased in all specialties assessed except paediatrics and anaesthesiology. There is also a growing urban-rural disparity in physician supply in all specialties assessed except paediatrics. Additional measures may be needed to resolve these issues and improve physician distribution in Japan.

\section{INTRODUCTION}

The presence of inequities in the geographical distribution of physicians is a major social problem in many countries. ${ }^{1-4}$ In Japan, the geographical disparity in physician supply has long been recognised as a serious flaw

\section{Strengths and limitations of this study}

This study longitudinally examined specialty-specific changes in the geographical distribution of Japanese physicians with adjustments for healthcare demand according to population structure.

- The adjustment method used in this study was previously verified, and enabled adjustment for healthcare demand according to age strata using health expenditure per capita.

- Both age and sex were included in the calculation of the adjustment coefficients to increase the accuracy of adjustments.

- There was a lack of information on the physicians' working conditions, such as whether a physician worked full time or part-time.

- It is difficult to generalise our adjustment coefficients to other countries as they were calculated using Japanese health expenditure, but the adjustment method itself may have applications in other countries.

in the healthcare provision system. ${ }^{5}{ }^{6}$ The lack of regulations that dictate where individual physicians work in Japan has led to the concentration of physicians in urban regions and a shortfall in rural areas, thereby resulting in uneven access to healthcare throughout the country. ${ }^{5}{ }^{6}$ On the other hand, Japan has entered a period of population decline, ${ }^{7}$ and an oversupply of physicians is imminent if their numbers continue to rise at current rates. Attempts to control the total number of physicians have been met with resistance from various interest groups. ${ }^{8}$

In addition to the geographical disparity in physician supply, Japan also faces issues stemming from an uneven distribution of physicians among the clinical specialties. ${ }^{9}$ Previous studies from the US have reported that the geographical distribution of physicians varies according to clinical specialty. ${ }^{10}{ }^{11}$ Similarly, geographical disparities in the number of physicians in paediatrics, obstetrics and gynaecology (OB/GYN), and anaesthesiology have been documented in Japan. ${ }^{12}$ However, few 
studies have longitudinally examined the geographical distribution of physicians according to clinical specialty.

Although the number of physicians per 100000 population is generally used as an indicator when examining geographical disparities in physician supply, this measure involves a simple head count that does not account for the inherent variations in healthcare demand among the different age strata and sex. ${ }^{4}$ Furthermore, Japan's population is ageing at an unprecedented rate, which has resulted in its transformation into the world's first 'super-aged' society (where more than $21 \%$ of a country's population is aged 65 years and older). As a consequence, the population structure in Japan is undergoing dramatic changes, which has invariably led to changes to healthcare demand. We previously reported that Japan's healthcare demand increased by $22 \%$ from 2000 to 2014 amid worsening geographical disparity in physician supply. ${ }^{13}$ However, studies have yet to be conducted on the disparity in Japan's physician supply for different clinical specialties while accounting for the differences in healthcare demand.

This study aimed to longitudinally examine specialty-specific changes in the geographical distribution of physicians in Japan from 2000 to 2014 with adjustments for healthcare demand based on population structure.

\section{METHODS}

\section{Data source}

Data on the number of physicians were obtained from the Survey of Physicians, Dentists and Pharmacists conducted every 2 years by the Ministry of Health, Labour and Welfare (MHLW). Physicians in Japan are required to participate in this survey, which includes information on each physician's specialty and the type and location (municipality) of their workplace. Population data (age, sex and location of residence) were extracted from the Annual Report of the National Basic Resident Registration System published by the Ministry of Internal Affairs and Communications, and data on the number of births were obtained from the Annual Report of Vital Statistics published by the MHLW. We also acquired data on national health expenditure per capita according to patient age and sex in 2013 from the MHLW. The total area of habitable land was ascertained from statistical reports on land areas of prefectures and municipalities by the Geospatial Information Authority of Japan.

\section{Physicians and population}

We targeted physicians working in clinical facilities (hospitals and clinics) and excluded physicians working in non-clinical facilities (eg, research centres and government offices). The following clinical specialties were included in analysis: internal medicine, surgery, orthopaedics, OB/GYN, paediatrics and anaesthesiology. Internal medicine, surgery and orthopaedics were selected because these departments generally have more physicians than other departments. The remaining three specialties were selected because of their previously reported geographical disparities in physician supply throughout Japan. ${ }^{12}$

In addition to the total population, we also analysed the female population, paediatric population $(<15$ years of age) and the number of births. With the exception of the number of births, all study populations were adjusted for healthcare demand. We calculated the number of OB/GYN specialists per 100000 female population and per 100000 births, the number of paediatricians per 100 000 paediatric population and the number of physicians per 100000 population for each of the other clinical specialties.

\section{Geographical unit}

The geographical unit of analysis was the secondary medical area (SMA). The Japanese government has designated three regional levels of healthcare provision. Primary medical areas are geographical units where primary care is provided, and are demarcated by municipal borders. Tertiary medical areas are geographical units that provide advanced medical care, and are demarcated by prefectural borders. SMAs are set between primary and tertiary medical areas, and are regions where general medical care (such as inpatient care) is provided; these areas are composed of multiple municipalities. Each prefectural government stipulates the geographical and demographic range of the SMAs within their prefecture. As a result, the boundaries of each SMA can be altered in response to changes in healthcare demand. SMAs have been previously used to examine the inequities in physician supply in Japan. ${ }^{6}{ }^{14}$ Because the number of SMAs varies slightly over time, this study was conducted using the 349 SMAs designated in 2012.

\section{Analytical methods}

This retrospective study longitudinally examined the changes in the geographical distribution of the number of physicians by clinical specialty among Japan's SMAs from 2000 to 2014. The primary outcomes were the overall number of physicians per 100000 population and the trends in Gini coefficients (indicating geographical disparity) for each specialty during the study period. The secondary outcomes were the changes in physician numbers during the same period for subgroups that were categorised according to regional characteristics (urbanrural classification and initial physician supply).

The population was first adjusted using adjustment coefficients of healthcare demand, which were calculated based on the health expenditure per capita stratified by age and sex through a previously described method. ${ }^{13}$ Health expenditure per capita is likely indicative of the general workload of healthcare providers. ${ }^{15}$ These expenditures include those for both inpatient and outpatient services, and account for variations in patient health status. ${ }^{13}$ The demand-adjusted population (DAP) was generated by multiplying the raw population with the adjustment coefficients. 
Next, geographical disparity was assessed using the Gini coefficient. This indicator, which is widely used to examine disparity in the field of economics, has been applied to analyse geographical disparity in physician supply. ${ }^{5}{ }^{16-18}$ We calculated the Gini coefficients for each specialty every 2 years from 2000 to 2014 . The coefficients, which take a value from 0 (indicating complete equality) to 1 (indicating complete inequality), measure departure from a uniform distribution by drawing Lorenz curves. ${ }^{17}$ If the curves of two time points intersect, conclusions cannot be made as to whether or not the inequity of distribution is increasing. ${ }^{18}$ Thus, we plotted two Lorenz curves (one each for 2000 and 2014) for each clinical specialty.

Finally, a subgroup analysis was conducted by dividing SMAs into groups according to two regional characteristics. Using the method described in Sasaki et al, ${ }^{19}$ we classified each SMA into one of four groups based on whether the SMA was an urban or rural area, and whether the SMA had a higher or lower initial physician supply in 2000. An SMA was designated an urban area (or a rural area) if its population density was higher (or lower) than the median value in all SMAs. The population density of each SMA was calculated using the total area of habitable land and the population in 2000. Next, an SMA was designated as having a higher (or lower) initial physician supply if the number of physicians per 100000 population was higher (or lower) than the median number of physicians per 100000 population in all SMAs. The following four groups were analysed: group 1, which comprised urban areas with higher initial physician supply; group 2, which comprised rural areas with higher initial physician supply; group 3, which comprised rural areas with lower initial physician supply; and group 4, which comprised urban areas with lower initial physician supply. Data from 2000 were used for both the population and physicians. In this subgroup analysis, we compared the intergroup changes in the number of physicians per 100000 population between 2000 and 2014.

All analyses were performed using R statistical software (V.3.2.2).
RESULTS

Table 1 shows the population sizes of the total population, female population and paediatric population before and after applying the adjustment coefficients in 2000 and 2014. The adjustment coefficients for the different age strata and sex are provided in online supplementary appendix figure. Before adjustment, the total population did not substantially change throughout the study period. In contrast, the demand-adjusted total population increased by $23.7 \%$ between 2000 and 2014. The number of births, which was not adjusted for healthcare demand, decreased by $15.7 \%$. The paediatric population declined by $11.1 \%$ over the study period both before and after adjusting for healthcare demand.

Table 2 shows the overall number of physicians and the number of physicians per 100000 population in 2000 and 2014. The overall number of all physicians increased by $22.1 \%$ over the study period. Similarly, the number of all physicians per 100000 population increased by $21.7 \%$. However, the number of all physicians per 100000 DAP decreased by $1.3 \%$. The number of physicians per 100000 DAP in surgery and OB/GYN declined by $26 \%$ and $17.5 \%$, respectively. In contrast, the number of OB/ GYN specialists per 100000 births increased by $23.1 \%$ due to the declining number of births. The number of physicians per $100000 \mathrm{DAP}$ in paediatrics and anaesthesiology increased by $33.3 \%$ and $21.1 \%$, respectively.

Table 3 shows the trends in Gini coefficients for the number of physicians per 100000 population in the SMAs by clinical specialty. There were no substantial changes in the Gini coefficients for the numbers of orthopaedists, paediatricians, and anaesthesiologists per 100000 DAP. However, inequity increased in the geographical distribution of internists, surgeons and OB/GYN specialists (for both the female population and the number of births). In each of these three specialties, the Lorenz curve in 2014 tended to deteriorate more than the curve in 2000 without intersection between the two curves (figures not shown). When comparing the Gini coefficients before and after adjusting for healthcare demand, the trends in the coefficients were similar for each clinical specialty. However, the postadjustment Gini coefficients for all

Table 1 Population sizes in 2000 and 2014 before and after adjustment for healthcare demand

\begin{tabular}{|c|c|c|c|c|c|c|c|}
\hline \multirow[b]{2}{*}{ Year } & \multicolumn{4}{|c|}{ Before adjustment } & \multicolumn{3}{|c|}{ After adjustment } \\
\hline & $\begin{array}{l}\text { Total } \\
\text { population }\end{array}$ & $\begin{array}{l}\text { Female } \\
\text { population }\end{array}$ & $\begin{array}{l}\text { Paediatric } \\
\text { population* }\end{array}$ & Births $†$ & $\begin{array}{l}\text { Total } \\
\text { population }\end{array}$ & $\begin{array}{l}\text { Female } \\
\text { population }\end{array}$ & $\begin{array}{l}\text { Paediatric } \\
\text { population* }\end{array}$ \\
\hline 2014 & 126434634 & 56670449 & 16489385 & 1003474 & 125837379 & 60902189 & 7594643 \\
\hline Increase in number (\%) & $\begin{array}{l}363329 \\
(0.3 \%)\end{array}$ & $\begin{array}{l}1474190 \\
(2.7 \%)\end{array}$ & $\begin{array}{l}-2063890 \\
(-11.1 \%)\end{array}$ & $\begin{array}{l}-186690 \\
(-15.7 \%)\end{array}$ & $\begin{array}{l}24140085 \\
(23.7 \%)\end{array}$ & $\begin{array}{l}12553142 \\
(26 \%)\end{array}$ & $\begin{array}{l}-951969 \\
(-11.1 \%)\end{array}$ \\
\hline
\end{tabular}

Healthcare demand was adjusted by multiplying the raw population with adjustment coefficients that were calculated using health expenditure per capita stratified by age and sex.

*Paediatric population: all residents aged below 15 years.

†The number of births was not adjusted for healthcare demand. 


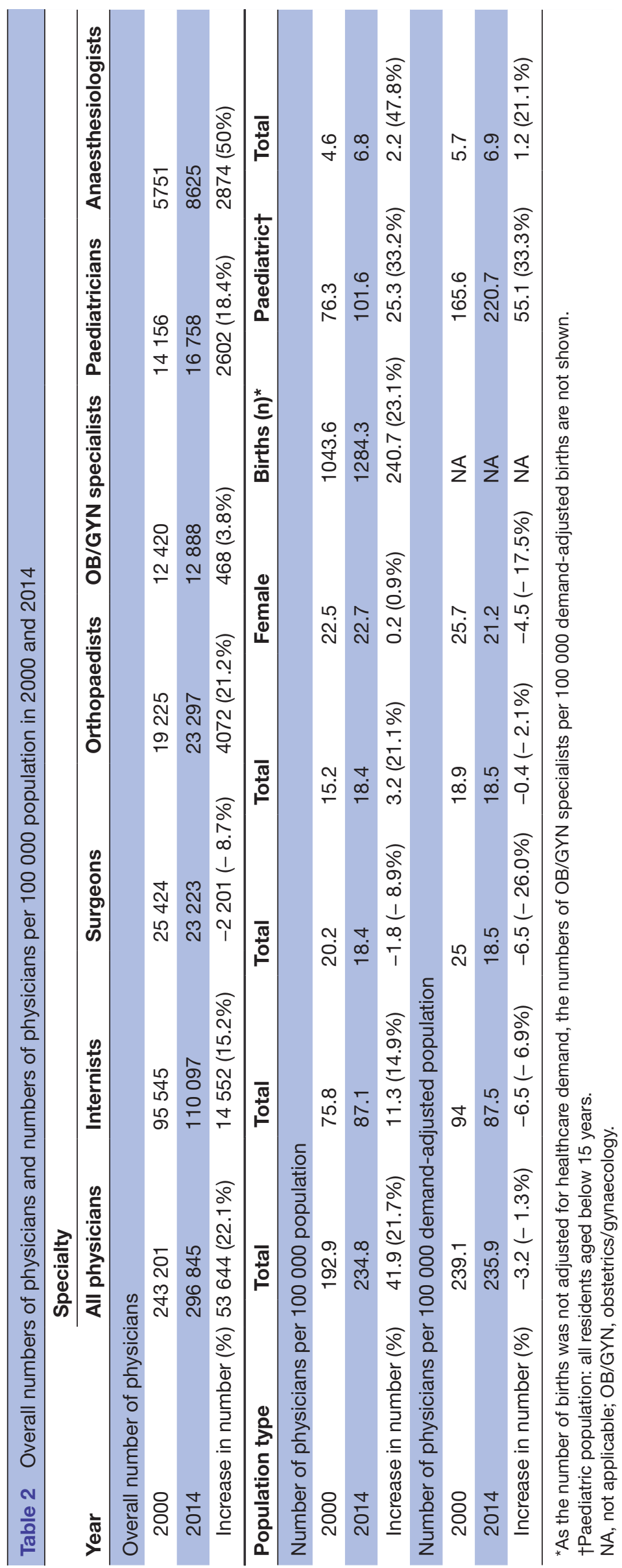

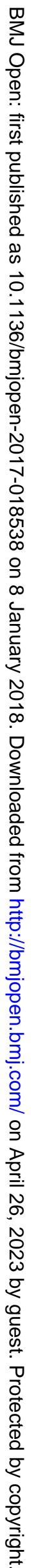


Table 3 Trends in Gini coefficients for the number of physicians per 100000 population in secondary medical areas by clinical specialty

\begin{tabular}{|c|c|c|c|c|c|c|c|c|c|}
\hline Year & 2000 & 2002 & 2004 & 2006 & 2008 & 2010 & 2012 & 2014 & $\begin{array}{l}\begin{array}{l}2000-2014 \\
\text { changes }\end{array} \\
\end{array}$ \\
\hline \multicolumn{10}{|l|}{ Number of physicians per 100000 population } \\
\hline All physicians & 0.195 & 0.193 & 0.194 & 0.194 & 0.199 & 0.202 & 0.205 & 0.206 & 0.011 \\
\hline Internists & 0.183 & 0.179 & 0.177 & 0.175 & 0.177 & 0.179 & 0.183 & 0.181 & -0.002 \\
\hline Surgeons & 0.204 & 0.202 & 0.197 & 0.190 & 0.194 & 0.206 & 0.210 & 0.209 & 0.005 \\
\hline Orthopaedists & 0.202 & 0.201 & 0.196 & 0.191 & 0.195 & 0.193 & 0.192 & 0.196 & -0.006 \\
\hline OB/GYN specialists (per female population) & 0.226 & 0.218 & 0.226 & 0.240 & 0.260 & 0.263 & 0.266 & 0.270 & 0.043 \\
\hline OB/GYN specialists (per number of births)* & 0.231 & 0.220 & 0.227 & 0.225 & 0.243 & 0.243 & 0.248 & 0.250 & 0.019 \\
\hline Paediatricians (per paediatric population) & 0.248 & 0.244 & 0.239 & 0.243 & 0.246 & 0.244 & 0.247 & 0.246 & -0.003 \\
\hline Anaesthesiologists & 0.445 & 0.435 & 0.438 & 0.433 & 0.434 & 0.428 & 0.432 & 0.429 & -0.016 \\
\hline \multicolumn{10}{|c|}{ Number of physicians per 100000 demand-adjusted population } \\
\hline All physicians & 0.212 & 0.210 & 0.214 & 0.219 & 0.227 & 0.231 & 0.234 & 0.237 & 0.025 \\
\hline Internists & 0.186 & 0.182 & 0.185 & 0.184 & 0.191 & 0.194 & 0.199 & 0.199 & 0.013 \\
\hline Surgeons & 0.204 & 0.202 & 0.198 & 0.189 & 0.199 & 0.213 & 0.218 & 0.219 & 0.015 \\
\hline Orthopaedists & 0.215 & 0.212 & 0.208 & 0.204 & 0.211 & 0.211 & 0.210 & 0.213 & -0.002 \\
\hline OB/GYN specialists (per female population) & 0.254 & 0.247 & 0.255 & 0.272 & 0.292 & 0.296 & 0.299 & 0.303 & 0.049 \\
\hline Paediatricians (per paediatric population) & 0.244 & 0.240 & 0.235 & 0.240 & 0.243 & 0.240 & 0.243 & 0.242 & -0.002 \\
\hline Anaesthesiologists & 0.456 & 0.447 & 0.451 & 0.448 & 0.449 & 0.445 & 0.450 & 0.447 & -0.009 \\
\hline
\end{tabular}

${ }^{*}$ As the number of births was not adjusted for healthcare demand, the numbers of OB/GYN specialists per 100000 demand-adjusted births are not shown.

OB/GYN, obstetrics/gynaecology.

clinical specialties (except for paediatrics) were higher than their preadjustment values.

Table 4 summarises the changes in the numbers of physicians per 100000 population in the four groups of SMAs. Detailed descriptive statistics of the four groups are provided in the online supplementary appendix table. Figure 1 shows the temporal increases (2000-2014) in the number of physicians by clinical specialty in each group of SMAs. The temporal increases in the number of internists and orthopaedists were similar to those for all physicians. The overall number of surgeons decreased in all groups except for group 4, and the number of surgeons per 100000 DAP decreased by $20 \%-30 \%$ in all groups. As shown in table 4, the number of surgeons per 100000 DAP in group 3 (11.9) was approximately half of the corresponding number in group 1 (23.2) in 2014. In all groups, the number of OB/GYN specialists per 100 000 demand-adjusted female population decreased, but the number of OB/GYN specialists per 100000 births increased. The number of paediatricians per 100000 demand-adjusted paediatric population increased more in the rural SMAs than in the urban SMAs. The number of anaesthesiologists per 100000 DAP increased in all groups; in particular, the number in group 4 increased by more than two times that of the other groups. In all clinical specialties except paediatrics and anaesthesiology, group 3 had the highest decrease in the number of physicians per $100000 \mathrm{DAP}$. The 2014-2000 difference and ratio of the number of physicians per 100000 DAP between groups 3 and 4 increased in all clinical specialties except paediatrics.

\section{DISCUSSION}

The four major findings of this study are as follows: First, the DAP increased by $23.7 \%$ between 2000 and 2014, whereas the demand-adjusted paediatric population decreased by $11.1 \%$. Second, the number of physicians per 100000 DAP decreased in all clinical specialties except paediatrics and anaesthesiology. The largest increase $(33.3 \%)$ was observed in paediatrics. Third, the geographical disparity in the number of physicians per 100000 DAP did not decline in all clinical specialties, and had in fact increased in internal medicine, surgery and OB/GYN. Fourth, rural areas with lower initial physician supply had the highest decrease in the number of physicians per 100000 DAP compared with other areas in all clinical specialties except paediatrics and anaesthesiology. In contrast, urban areas with lower initial physician supply had the lowest decrease in internal medicine, surgery, orthopaedics and OBG/GYN, but the highest increase in anaesthesiology.

The population used in this study was adjusted for healthcare demand among the different age strata and sex using a previously described method. ${ }^{13}$ Although several studies have examined the demand-adjusted 
Table 4 Descriptive statistics of the number of physicians per 100000 population in the four groups of secondary medical areas in 2000 and 2014

Before adjustment

\section{4}

After adjustment

2014

Total number of physicians per 100000 population

$\begin{array}{lllll}\text { Group 1 } & 247.0 & 297.9(20.6 \%) & 311.6 & 305.7(-1.9 \%) \\ \text { Group 2 } & 194.8 & 226.6(16.3 \%) & 213.9 & 203.3(-5.0 \%) \\ \text { Group 3 } & 124.6 & 142.1(14.0 \%) & 138.9 & 127.0(-8.6 \%) \\ \text { Group 4 } & 126.3 & 163.1(29.1 \%) & 166.9 & 171.9(3 \%)\end{array}$

Number of internists per 100000 population

\begin{tabular}{ccccc} 
Group 1 & 95.2 & $108(13.4 \%)$ & 120.1 & $110.8(-7.7 \%)$ \\
Group 2 & 79.8 & $87.5(9.6 \%)$ & 87.6 & $78.5(-10.4 \%)$ \\
\hline Group 3 & 54.0 & $59.1(9.4 \%)$ & 60.2 & $52.8(-12.3 \%)$ \\
\hline Group 4 & 49.6 & $61.4(23.8 \%)$ & 65.5 & $64.7(-1.2 \%)$
\end{tabular}

Number of surgeons per 100000 population

$\begin{array}{lllll}\text { Group 1 } & 25.2 & 22.6(-10.3 \%) & 31.8 & 23.2(-27.0 \%) \\ \text { Group 2 } & 21.8 & 19.3(-11.5 \%) & 24 & 17.3(-27.9 \%) \\ \text { Group 3 } & 15.3 & 13.3(-13.1 \%) & 17.1 & 11.9(-30.4 \%) \\ \text { Group 4 } & 12.9 & 12.7(-1.6 \%) & 17 & 13.3(-21.8 \%)\end{array}$

Number of orthopaedists per 100000 population

$\begin{array}{ccccc}\text { Group 1 } & 18.6 & 22.4(20.4 \%) & 23.5 & 23.0(-2.1 \%) \\ \text { Group 2 } & 16.6 & 19.2(15.7 \%) & 18.2 & 17.2(-5.5 \%) \\ \text { Group 3 } & 10.8 & 12.6(16.7 \%) & 12 & 11.2(-6.7 \%) \\ \text { Group 4 } & 10.7 & 13.4(25.2 \%) & 14.2 & 14.2(0 \%) \\ \text { Number of OB/GYN specialists per 100 000 female population } & & \\ \text { Group 1 } & 28.4 & 28.9(1.8 \%) & 33.2 & 27.5(-17.2 \%) \\ \text { Group 2 } & 20.2 & 19.3(-4.5 \%) & 20.3 & 15.8(-22.2 \%) \\ \text { Group 3 } & 13.9 & 12.4(-10.8 \%) & 14.1 & 10.2(-27.7 \%) \\ \text { Group 4 } & 16.3 & 17(4.3 \%) & 20 & 16.7(-16.5 \%)\end{array}$

Number of OB/GYN specialists per 100000 births*

\begin{tabular}{ccccc} 
Group 1 & 1316.5 & $1578.9(19.9 \%)$ & NA & NA \\
Group 2 & 1051.3 & $1240.3(18 \%)$ & NA & NA \\
Group 3 & 714.9 & $849.8(18.9 \%)$ & NA & NA \\
Group 4 & 702.1 & $914.7(30.3 \%)$ & NA & NA \\
Number of paediatricians per 100 & 000 paediatric population & & \\
\hline Group 1 & 49.0 & $63.1(28.8 \%)$ & 211.5 & $272.3(28.7 \%)$ \\
Group 2 & 35.5 & $50.2(41.4 \%)$ & 158 & $221(39.9 \%)$ \\
Group 3 & 22.6 & $32.7(44.7 \%)$ & 100.7 & $144.8(43.8 \%)$ \\
Group 4 & 27.3 & $36.7(34.4 \%)$ & 117.6 & $159.4(35.5 \%)$
\end{tabular}

Number of anaesthesiologists per 100000 population

\begin{tabular}{lllll} 
Group 1 & 6.6 & $9.4(42.4 \%)$ & 8.3 & $9.7(16.9 \%)$ \\
Group 2 & 4.4 & $6.1(38.6 \%)$ & 4.8 & $5.5(14.6 \%)$ \\
Group 3 & 1.9 & $2.8(47.4 \%)$ & 2.1 & $2.5(19 \%)$ \\
Group 4 & 2.2 & $4.1(86.4 \%)$ & 2.9 & $4.3(48.3 \%)$ \\
\hline
\end{tabular}

Group 1: urban areas with higher initial physician supply; group 2: rural areas with higher initial physician supply; group 3: rural areas with lower initial physician supply; group 4: urban areas with lower initial physician supply.

The parenthesis represents the percentage of increase/decrease between 2000 and 2014.

*As the number of births was not adjusted for healthcare demand, the numbers of OB/GYN specialists per 100000 demand-adjusted births are not shown.

NA, not applicable; OB/GYN, obstetrics/gynaecology. 
A

@Physicians $₫$ Physicians / raw population $₫$ Physicians/demand-adjusted population 40.0

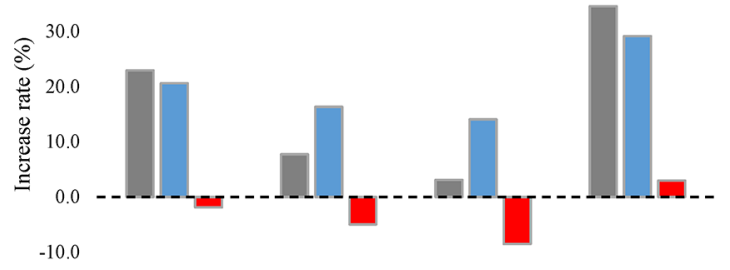

G 1

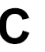

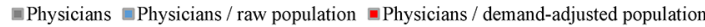
10.0

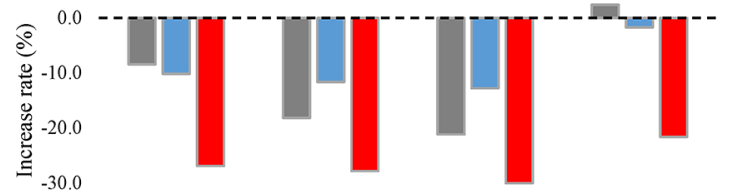

$-40.0$

G 2

G 3

G 4

Surgeons
D

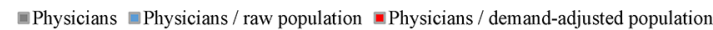
40.0

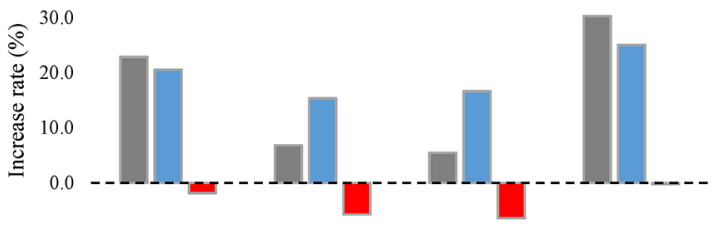

$-10.0$

Internists

mPhysicians 1 Physicians / raw population $₫$ Physicians / demand-adjusted population 40.0

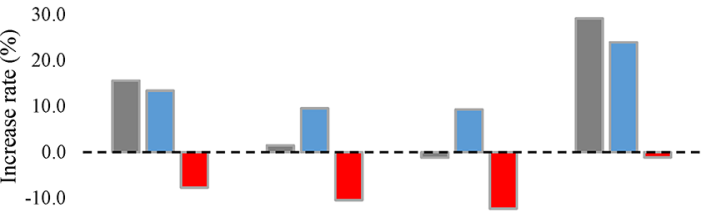

G

G 2

G 3

G 4

\section{Orthopaedists}

F OB/GYN specialists (per no. of births)

E $\mathrm{OB} / \mathrm{GYN}$ specialists (per female population)

$₫$ Physicians $\equiv$ Physicians / raw population $₫$ Physicians/demand-adjusted population 20.0

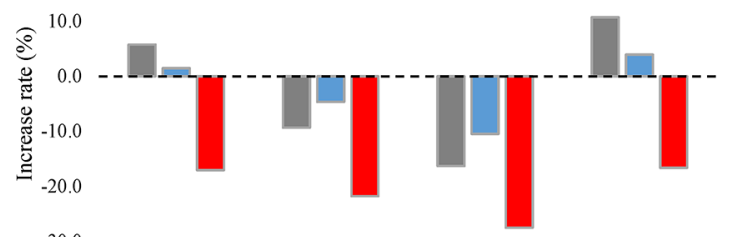

G 1

G 2

G 3

G 4

G Paediatricians (per paediatric population)

$₫$ Physicians $₫$ Physicians / raw population $₫$ Physicians / demand-adjusted population 50.0

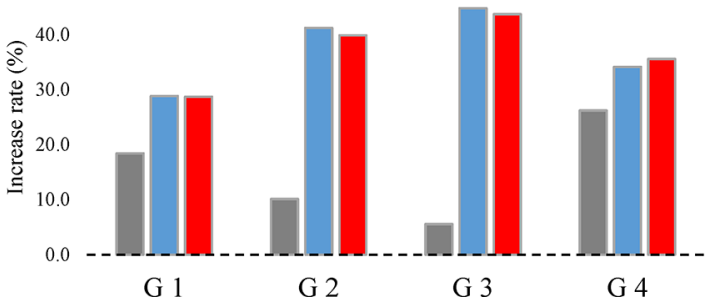

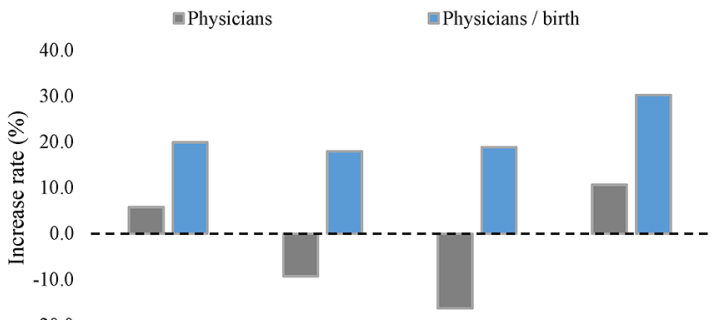

G 1

G 3

G 4

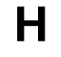

Anaesthesiologists

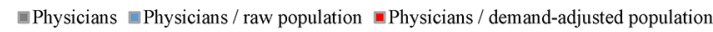
100.0

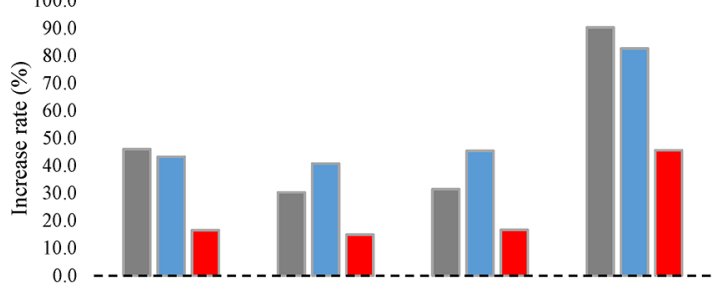

G 1

G 2

G 3

G 4

Figure 1 (A-H) Temporal increases in physician numbers from 2000 to 2014 for the four groups of secondary medical areas. Group 1 (G1): urban areas with higher initial physician supply; group 2 (G2): rural areas with higher initial physician supply; group 3 (G3): rural areas with lower initial physician supply; group 4 (G4): urban areas with lower initial physician supply. *As the number of births was not adjusted for healthcare demand, the numbers of OB/GYN specialists per 100000 demand-adjusted births are not shown. OB/GYN: obstetrics/gynaecology.

geographical disparity in physician supply, ${ }^{15}{ }^{20}$ there is currently no gold standard method for adjustment. ${ }^{20}$ The method used in this study was previously verified, ${ }^{13}$ and enables adjustment for healthcare demand according to age strata. In addition, the inclusion of sex in the calculation of the coefficients may increase the accuracy of adjustments.
The number of physicians per 100000 DAP decreased in internal medicine, surgery, orthopaedics and OB/ GYN (per female population). The decline in physician supply was particularly large in surgery and OB/GYN, which corroborates previously reported downward trends in the numbers of physicians in these specialties. ${ }^{12}$ The distribution among specialties is affected by physician 
preference, experience and environment. For example, the shortage of surgeons may be influenced by the long working hours, high risk of medical litigation and low reward for surgical skill. ${ }^{21}$ Previous research has also shown that an increase in female physicians has affected the distribution of specialties because they are more likely to choose OB/GYN and paediatrics instead of surgery. ${ }^{22} 23$ In order to ensure a high number of both female and male physicians, we believe that improvements should be made to the working environment, such as a reduction in physician working hours by assigning more duties and responsibilities to non-physician health professionals. ${ }^{21}$ On the other hand, there was a large increase in the number of anaesthesiologists during the study period. Japan is experiencing an increasing need for anaesthesiologists due to the rising number of surgeries conducted, the increasing complexity of surgery owing to advances in surgical techniques and the overall ageing of patients, as well as the growing social expectations for safety in anaesthesia. ${ }^{24}$ The increase in anaesthesiologists may have been influenced by the growing number of female physicians. The increase in female anaesthesiologists from $26.7 \%$ to $37.6 \%$ during the study period is consistent with this possibility.

On the other hand, the number of paediatricians per 100000 demand-adjusted paediatric population and OB/GYN specialists per 100000 births increased substantially due to a decline in the paediatrics population and the number of births. The rate of paediatric population decline is expected to eventually exceed the rate of total population decline. ${ }^{25}$ It may therefore be more useful to ensure the optimal allocation of physicians instead of simply increasing their overall numbers.

Based on the analysis of Gini coefficients, there were no reductions in geographical disparity in the number of physicians per $100000 \mathrm{DAP}$ in all clinical specialties between 2000 and 2014. In particular, the inequity in physician supply increased in internal medicine, surgery and OB/GYN. The inequity in surgery and OB/GYN may have been influenced by the decrease or lack of increase in the overall number of physicians in these specialties. These findings suggest that the uneven distribution of physicians among the clinical specialties may exacerbate geographical disparities in physician supply. On the other hand, the number of internists increased at a rate that was comparable to the overall growth rate. The increase in geographical disparity may therefore be related to an increasing tendency toward physician specialisation in Japan. ${ }^{26}$ Although the overall number of general internists decreased from 74539 to 61317 over the study period, there was actually an increase from 21006 to 48780 physicians in internal medicine subspecialties such as pulmonary, cardiovascular and gastrointestinal medicine (data not shown). The geographical disparity in physician supply in these subspecialties is greater than the disparity in general internists. ${ }^{9}$ As a supplementary analysis, we calculated the Gini coefficients for general internal medicine and its subspecialties from 2000 to 2014. The results confirmed that the coefficient in the internal medicine subspecialties was consistently more than two times that of general internal medicine (general internal medicine: 0.173 in 2000 to 0.149 in 2014, internal subspecialties: 0.386 in 2000 to 0390 in 2014).

The rate of increase in the number of physicians per 100000 DAP in the urban areas was generally higher than in the rural areas. In all clinical specialties except paediatrics, both the difference and ratio in the number of physicians per 100000 DAP between groups 3 and 4 in 2014 were larger than the corresponding values in 2000. This indicates that the urban-rural disparity in physician supply widened over the study period. Group 3 had the lowest initial physician supply, and these regions may be facing a serious physician shortage. This issue should be explored further, and there may be a need for major reforms to ensure adequate physician supply to rural areas. It may also be important to implement measures in rural areas to improve physician productivity, reduce non-essential workload and implement technology-based systems such as telemedicine.

Prior to 2004, the vast majority of medical graduates joined a clinical specialty department (known as an Ikyoku) at their university that secures employment for the new graduates. Ikyoku generally dispatch physicians to other affiliated hospitals that are often located in rural areas. In this way, the Ikyoku were partly responsible for preventing a shortage of physicians in rural areas. On the other hand, medical graduates did not receive mandatory clinical training under this system. As a result, few graduates were able to acquire a wide range of medical skills through comprehensive and systematic training. ${ }^{27}$ In addition, training assessments were not adequately performed under the Ikyoku system. ${ }^{27}$ In order to improve the overall quality of clinical training throughout Japan, the MHLW mandated a standardised 2-year training programme in 2004. Furthermore, there was a large increase in the number of non-university hospitals that medical graduates could attend as part of this training programme after 2004. As a consequence, the graduates, now able to choose their training hospital after graduation, were less likely to select a university hospital for training. Due to the decreasing number of member physicians, it became more difficult for the Ikyoku to dispatch physicians to affiliate hospitals. ${ }^{14}$ Previous studies have also reported that the new programme may have increased the inequity in the geographical distribution of physicians. ${ }^{14} 28$ Similarly, this new programme may also have contributed to the lack of reduction in geographical disparity in this study.

The Japanese government has implemented several measures at the prefectural level aimed at reducing the geographical disparity in physician supply. In 2006, a 'Council for Regional Medicine' was established in each prefecture, and these councils include representatives of the prefectural and local governments, hospitals, medical associations, universities and residents. The councils discuss detailed measures for securing medical staff with a variety of hospitals, including university hospitals and 
public hospitals. Furthermore, a 'Support Centre for Community Medicine' was established in each prefecture in 2011 to secure and retain physicians. These centres adopt the role of 'control towers' to address the uneven distribution of physicians within each prefecture. Specifically, the centres are responsible for supporting career advancement for physicians working in rural areas, acting as general liaisons for engaging new physicians and providing general work information. In addition, the government has raised the regional quota of medical school admissions from 64 students in 2005 to 1617 students in 2016. The students are obligated to work in a rural area or a designated specialty (such as OB/GYN) for 9 years after graduating in return for financial assistance for their studies. ${ }^{29}$ As the programme is relatively new, it remains unclear as to whether the increase in quotas will lead to reductions in the geographical disparity of physicians.

There are several limitations in this research. First, the adjustment coefficients may continue to change in the future. However, the coefficients did not fluctuate considerably during the study period. In addition, it may be difficult to generalise our adjustment coefficients to other countries as they were calculated using Japanese health expenditure. Nevertheless, the adjustment method itself may have applications in other countries. Second, there was a lack of information on the physicians' working conditions, such as whether a physician worked full time or part-time. It may be beneficial for future studies to incorporate mean physician working hours. Third, our analysis had focused on specialties with a large number of physicians and previously reported geographical disparities. This may have introduced selection bias as other specialties may not have experienced the same geographical disparities described in this study. Finally, there may be other ways to divide the SMAs for the subgroup analysis. However, our subgroup analysis was based on the categorization used in a previous study, ${ }^{19}$ and provided an intuitive understanding of the differences in group characteristics.

\section{CONCLUSION}

Between 2000 and 2014, the number of physicians per 100000 DAP in Japan decreased in all specialties assessed except paediatrics and anaesthesiology. There is also a growing urban-rural disparity in physician supply in all specialties assessed except paediatrics. In consideration of the rapidly ageing population and the resulting changes in population structure, additional measures may be needed to resolve these issues and improve physician distribution in Japan.

Contributors KH contributed to the study conception and design, data collection, analysis, interpretation and drafting of the manuscript. SK and NS contributed to the data collection and data management. YI contributed to the study design, data acquisition and interpretation. All authors critically revised the manuscript and approved the final version.
Funding This work was supported in part by a Health Sciences Research Grant from the Ministry of Health, Labour and Welfare of Japan (Grant number: H27-iryoippan-001), a Grant-in-Aid for Scientific Research from the Japan Society for the Promotion of Science (Grant number: [A]16H02634), and RISTEX, Japan Science and Technology Agency(2014-2017). The corresponding author had full access to all the data in the study and had final responsibility for the decision to submit for publication.

Competing interests None declared.

Ethics approval Ethics committee approval was waived for this study because all of the data are publicly available online and comprise only aggregate values without any personally identifiable information.

Provenance and peer review Not commissioned; externally peer reviewed.

Data sharing statement No additional data are available.

Open Access This is an Open Access article distributed in accordance with the Creative Commons Attribution Non Commercial (CC BY-NC 4.0) license, which permits others to distribute, remix, adapt, build upon this work non-commercially, and license their derivative works on different terms, provided the original work is properly cited and the use is non-commercial. See: http://creativecommons.org/ licenses/by-nc/4.0/

(C) Article author(s) (or their employer(s) unless otherwise stated in the text of the article) 2018. All rights reserved. No commercial use is permitted unless otherwise expressly granted.

\section{REFERENCES}

1. Isabel C, Paula V. Geographic distribution of physicians in Portugal. Eur J Health Econ 2010;11:383-93.

2. Kanchanachitra $\mathrm{C}$, Lindelow $\mathrm{M}$, Johnston $\mathrm{T}$, et al. Human resources for health in southeast Asia: shortages, distributional challenges, and international trade in health services. Lancet 2011;377:769-81.

3. Ricketts TC. The migration of physicians and the local supply of practitioners: a five-year comparison. Acad Med 2013;88:1913-8.

4. Pitblado JR, Pong RW. Geographic distribution of physicians in Canada. Sudbury, Ontario, Canada: Centre for Rural and Northern Health Research, Laurentian University, 1999.

5. Kobayashi Y, Takaki H. Geographic distribution of physicians in Japan. Lancet 1992;340:1391-3.

6. Tanihara S, Kobayashi Y, Une H, et al. Urbanization and physician maldistribution: a longitudinal study in Japan. BMC Health Serv Res 2011;11:260

7. National Institute of Population and Social, Security Research. population projection for Japan:2011-2060. 2012 http://www.ipss.go. jp/syoushika/tohkei/newest04/gh2401.pdf (accessed 29 Feb 2016).

8. Asano N, Kobayashi Y, Kano K. Issues of intervention aimed at preventing prospective surplus of physicians in Japan. Med Educ 2001;35:488-94.

9. Matsumoto M, Inoue K, Bowman R, et al. Self-employment, specialty choice, and geographical distribution of physicians in Japan: a comparison with the United States. Health Policy 2010;96:239-44.

10. Rosenthal MB, Zaslavsky A, Newhouse JP. The geographic distribution of physicians revisited. Health Serv Res 2005; 40:1931-52.

11. Schwartz WB, Newhouse JP, Bennett BW, et al. The changing geographic distribution of board-certified physicians. N Engl J Med 1980;303:1032-8.

12. Study group on the supply and demand of physicians of the Ministry of Health, Labour and Welfare. The study group report on the supply and demand of physicians 2006. http://www.mhlw.go.jp/shingi/2006/ 07/dl/s0728-9c.pdf (accessed 16 Apr 2017).

13. Hara K, Otsubo T, Kunisawa S, et al. Examining sufficiency and equity in the geographic distribution of physicians in Japan: a longitudinal study. BMJ Open 2017;7:e013922.

14. Sakai R, Tamura H, Goto R, et al. Evaluating the effect of Japan's 2004 postgraduate training programme on the spatial distribution of physicians. Hum Resour Health 2015;13:5.

15. Gravelle $H$, Sutton $M$. Inequality in the geographical distribution of general practitioners in England and Wales 1974-1995. J Health Serv Res Policy 2001;6:6-13.

16. Anand S, Fan VY, Zhang J, et al. China's human resources for health: quantity, quality, and distribution. Lancet 2008;372:1774-81.

17. Mauguen A, Begg CB. Using the lorenz curve to characterize risk predictiveness and etiologic heterogeneity. Epidemiology 2016;27:531-7.

18. Theodorakis PN, Mantzavinis GD, Rrumbullaku L, et al. Measuring health inequalities in Albania: a focus on the distribution of general practitioners. Hum Resour Health 2006;4:5. 
19. Sasaki H, Otsubo T, Imanaka Y. Widening disparity in the geographic distribution of pediatricians in Japan. Hum Resour Health 2013;11:59.

20. Kephart G, Asada Y. Need-based resource allocation: different need indicators, different results? BMC Health Serv Res 2009;9:122.

21. Hanazaki K, Tominaga R, Nio M, et al. Report from the committee for improving the work environment of japanese surgeons: survey on effects of the fee revision for medical services provided by surgeons. Surg Today 2013;43:1209-18.

22. Fukuda $Y$, Harada T. Gender differences in specialty preference and mismatch with real needs in Japanese medical students. BMC Med Educ 2010;10:15.

23. Jefferson L, Bloor K, Maynard A. Women in medicine: historical perspectives and recent trends. Br Med Bull 2015;114:5-15.

24. Tabayashi K, Sai S, Iguchi A, et al. Responding to lack of anesthesiologists thinking about the current situation of anesthesiologists shortage from the standpoint of surgeons [in
Japanese]. Journal of Japanese Association for Operating Room Technology 2006;27:288-91.

25. National Institute of Population and Social Security Research in Japan. Population projections for Japan (April 2017), 2017. (accessed 14 Apr 2017).

26. Koike S, Matsumoto S, Kodama T, et al. Specialty choice and physicians' career paths in Japan: an analysis of National Physician Survey data from 1996 to 2006. Health Policy 2010;98:236-44.

27. Ministry of Health, Labour and Welfare. A history of post-graduate clinical training system [in Japanese]. http://www.mhlw.go.jp/topics/ bukyoku/isei/rinsyo/hensen/ (accessed 1 Sep 2017).

28. Toyabe S. Trend in geographic distribution of physicians in Japan. Int $J$ Equity Health 2009;8:5.

29. Matsumoto M, Takeuchi K, Tanaka J, et al. Follow-up study of the regional quota system of Japanese medical schools and prefecture scholarship programmes: a study protocol. BMJ Open 2016;6:e011165. 